\title{
Association of Final Discharge Blood Pressure with Post-discharge Outcomes Using Electronic Medical Record Data: a Retrospective Study
}

\author{
Maleka Khambaty, $\mathrm{MD}^{7}$ and Nishant Sahni, $M D, M S^{1,2}$ \\ 'University of Minnesota Medical Center, Minneapolis, MN, USA; ${ }^{2}$ Health East System, St. Paul, MN, USA.
}

$\begin{array}{ll}\text { Abbreviations } & \\ \text { EMR } & \text { Electronic medical record } \\ \text { GFR } & \text { Glomerular filtration rate } \\ \text { SBP } & \text { Systolic blood pressure } \\ \text { AHRQ } & \text { Agency for Health Care Research and Quality } \\ \text { AOR } & \text { Adjusted odds ratio } \\ \text { UOR } & \text { Unadjusted odds ratio }\end{array}$

J Gen Intern Med 34(8):1373-5

DOI: $10.1007 / \mathrm{s} 11606-019-04981-0$

(c) Society of General Internal Medicine 2019

\section{INTRODUCTION}

Abnormal blood pressures are common at hospital discharge; however, few studies have examined the association between discharge systolic blood pressure (SBP) and short-term postdischarge outcomes. ${ }^{1,2}$ We examined the association between the last SBP measured during a hospitalization and the odds of 30-day readmission and/or mortality.

\section{METHODS}

The institutional review board at the University of Minnesota approved this study. We included 94,974 emergent hospital admissions from 57,063 patients within a six-hospital network in the Minneapolis/St. Paul area, MN, over 4 years (20122016). We excluded non-emergent admissions, patients less than 18 years of age, those who did not consent to their medical record being used for research purposes, or had less than 31 days of follow-up mortality data. We also excluded patients that died during their hospital stay or were discharged to hospice. Our database had complete death records from 2011 onwards for all Minnesotans. In order to avoid bias introduced by repeated measurements from a single patient, we randomly sampled the original dataset to include only one encounter for each patient. SBP was stratified as $<80 \mathrm{mmHg}$, 80-100 mmHg, 100-110 mmHg, 110-120 mmHg, 120$140 \mathrm{mmHg}, 140-160 \mathrm{mmHg}, 160-180 \mathrm{mmHg}$, and > $180 \mathrm{mmHg}$. We used logistic regression to assess the relationship between SBP and death or readmission within 30 days of

Prior Presentations None.

Published online April 22, 2019 the index hospitalization, adjusting for age, sex, race, body mass index, length of stay, AHRQ comorbidities, estimated glomerular filtration rate (eGFR), serum albumin, hemoglobin, sodium, bilirubin, and platelet counts (R Studio, V 1.1.463).

\section{RESULTS}

Patient demographic and clinical characteristics are shown in Table 1. Physiological parameters or biochemical values were not significantly different amongst the two groups. Patients with 30-day death or readmission had worse renal function (creatinine 1.0 vs. $1.4, p<0.001$ ) and higher glucose values (112 mg/dL vs. $125 \mathrm{mg} / \mathrm{dL}, p<0.001)$. Table 2 shows the association of discharge systolic blood pressure with 30-day mortality and readmission. The highest odds of 30-day readmission or death were associated with SBP of less than $80 \mathrm{mmHg}$ (adjusted OR 4.47, 95\% CI 3.03-6.59). Discharge SBP of greater than 140 also had higher odds of adverse events (for SBP 140-160, 160-180, and > 180, UOR 1.09, CI 1.031.15, UOR 1.42, CI 1.30-1.56, and UOR 1.62, CI 1.30-2.02 respectively). However, after controlling for covariates, this significance was lost (AOR 0.88, CI 0.80-0.97, AOR 0.93, CI 0.79-1.08, and AOR 1.17, CI 0.81-1.68 respectively).

\section{DISCUSSION}

Currently, there are no guidelines as to what constitutes a "safe" discharge SBP. 1, 3, 4 In our study, a discharge SBP of 110-140 mmHg was associated with the lowest odds of adverse events in the 30 days post-hospitalization. The odds of 30-day mortality/readmission increased at SBPs < $110 \mathrm{mmHg}$ - with the highest odds observed at SBP values $<80 \mathrm{mmHg}$. With SBP > $140 \mathrm{mmHg}$, the unadjusted odds of adverse events increased with the SBP and peaked at SBP > $180 \mathrm{mmHg}$. However, the adjusted odds were not significantly higher for SBPs above $140 \mathrm{mmHg}$. This suggests that the higher rates of adverse post-discharge events observed in this range were driven by patient comorbidities rather than the SBP.

Although we adjusted for a number of the most relevant variables, unmeasured variables could be potential 
Table 1 Characteristics of Discharged Patients Stratified by 30-Day Death or Readmission

\begin{tabular}{|c|c|c|c|}
\hline $\begin{array}{l}\text { Stratified by death or readmission within } \\
30 \text { days }\end{array}$ & $\begin{array}{l}\text { Patients without 30-day death or read- } \\
\text { mission }\end{array}$ & $\begin{array}{l}\text { Patients with 30-day death or read- } \\
\text { mission }\end{array}$ & $p$ value \\
\hline Number of patients & 50,161 & 3629 & \\
\hline \multicolumn{4}{|l|}{ Demographics } \\
\hline Age in years (mean $(\mathrm{SD}))$ & $58.68(20.11)$ & $66.62(18.04)$ & $<0.001$ \\
\hline Male $(\%)$ & $24,056(47.96)$ & 1789 (49.30) & 0.123 \\
\hline \multicolumn{4}{|l|}{ Race/ethnicity (\%) } \\
\hline White & $42,487(84.70)$ & $3142(86.58)$ & \\
\hline African American & $3559(7.10)$ & $225(6.20)$ & \\
\hline Asian & $1217(2.43)$ & $81(2.23)$ & \\
\hline American Indian/Alaskan Native & $635(1.27)$ & $39(1.07)$ & \\
\hline Hispanic/Latino & $882(1.76)$ & $55(1.52)$ & \\
\hline Native Hawaiian/Pacific Islander & $48(0.10)$ & $5(0.14)$ & \\
\hline \multicolumn{4}{|l|}{ Clinical data } \\
\hline Systolic BP (mmHg, mean (SD)) & $127.2(18.6)$ & $126.0(20.8)$ & $<0.001$ \\
\hline Diastolic BP (mmHg, mean (SD)) & $72.5(12.7)$ & $70.3(13.6)$ & $<0.001$ \\
\hline Body mass index (mean (SD)) & $35.4(406.4)$ & $27.7(7.7)$ & 0.259 \\
\hline Length of stay in days (mean (SD)) & $3.7(4.0)$ & $5.2(5.1)$ & $<0.001$ \\
\hline \multicolumn{4}{|l|}{ Discharge disposition (\%) } \\
\hline Acute rehab facility & $731(1.46)$ & $49(1.35)$ & \\
\hline Expired & $0(0.00)$ & $0(0.00)$ & \\
\hline Home IV drug therapy & $431(0.86)$ & $42(1.16)$ & \\
\hline Home or self-care & $34,249(68.28)$ & $1407(38.77)$ & \\
\hline Home with home health care & $4390(8.75)$ & $552(15.21)$ & \\
\hline Home hospice & $0(0.00)$ & $0(0.00)$ & \\
\hline Left against medical advice & $487(0.97)$ & $35(0.96)$ & \\
\hline Psychiatric hospital & $607(1.21)$ & $39(1.07)$ & \\
\hline Another short-term hospital & $1102(2.20)$ & $226(6.23)$ & \\
\hline Skilled nursing facility & $6941(13.84)$ & $973(26.81)$ & \\
\hline Other & $1223(2.44)$ & $306(8.43)$ & \\
\hline
\end{tabular}

confounders. Furthermore, our findings do not apply to specific subgroups such as patients with heart failure, end-stage liver disease, or post-acute stroke populations. Finally, we may have underestimated readmission rates since we only had data for our hospital network.

Despite these limitations, our study highlights a significant association between abnormal discharge SBP $(<110 \mathrm{mmHg}$ or $>140 \mathrm{mmHg}$ ) and increased 30-day mortality and readmission. The higher rates of 30-day readmission and death observed in patients with discharge SBPs in the $140-180-\mathrm{mmHg}$ range may be at least partially due to their medical comorbidities. Ultimately, clinical trials are needed to further understand

Table 2 Systolic Blood Pressure and Its Relationship with Death or 30-Day Readmission

\begin{tabular}{|c|c|c|c|}
\hline $\begin{array}{l}\text { SBP } \\
\text { (mmHg) }\end{array}$ & $\begin{array}{l}\text { Number of } \\
\text { patients }\end{array}$ & $\begin{array}{l}\text { Adjusted odds } \\
\text { ratio }\end{array}$ & $\begin{array}{l}\text { Unadjusted odds } \\
\text { ratio }\end{array}$ \\
\hline$<80$ & 89 & $\begin{array}{l}4.47(3.03- \\
6.59)\end{array}$ & $5.10(3.98-6.55)$ \\
\hline $80-100$ & 3425 & $\begin{array}{l}2.03(1.83- \\
2.26)\end{array}$ & $1.83(1.70-1.96)$ \\
\hline $100-110$ & 7026 & $\begin{array}{l}1.39(1.26- \\
1.53)\end{array}$ & $1.22(1.15-1.30)$ \\
\hline $110-120$ & 10,238 & Reference & Reference \\
\hline $120-140$ & 20,369 & $\begin{array}{l}1.01(0.93- \\
1.10)\end{array}$ & $1.01(0.96-1.07)$ \\
\hline $140-160$ & 10,299 & $\begin{array}{l}0.88(0.80- \\
1.01)\end{array}$ & $1.09(1.03-1.15)$ \\
\hline $160-180$ & 2061 & $\begin{array}{l}0.93(0.79- \\
1.08)\end{array}$ & $1.42(1.30-1.56)$ \\
\hline$>180$ & 254 & $\begin{array}{l}1.17(0.81- \\
1.68)\end{array}$ & $1.62(1.30-2.02)$ \\
\hline
\end{tabular}

the nature of the link between discharge blood pressure and post-discharge adverse events.

Acknowledgements: We thank Tasneem Khambaty, PhD (Assistant Professor, Clinical Psychology, University of Maryland Baltimore County), for comments and editing that greatly improved the manuscript.

Corresponding Author: Maleka Khambaty, MD; University of Minnesota Medical Center, Mayo Mail Code 741, 420 Delaware St SE, Minneapolis, MN 55455, USA (e-mail: khamb003@umn.edu).

Author Contribution Dr. Sahni participated in the study design, data analysis, literature search, manuscript preparation, editing, and review. Dr. Khambaty participated in literature search, manuscript preparation, editing, and review.

Funding Sources Resources used for the research reported in this publication was supported by the National Center for Advancing Translational Sciences of the National Institutes of Health Award Number UL1TROOO114.

\section{Compliance with Ethical Standards:}

The institutional review board at the University of Minnesota approved this study.

Conflict of Interest: The authors declare that they do not have a conflict of interest.

Disclaimer: The content is solely the responsibility of the authors and does not necessarily represent the official views of the National Institutes of Health.

Prior Presentations: None. 


\section{REFERENCES}

1. Axon RN, Cousineau L, Egan BM. Prevalence and management of hypertension in the inpatient setting: A systematic review. J Hosp Med. 2011;6(7):417-422. https://doi.org/10.1002/jhm.804

2. Nguyen OK, Makam AN, Clark C, et al. Vital Signs Are Still Vital: Instability on Discharge and the Risk of Post-Discharge Adverse Outcomes. J Gen Intern Med. 2017;32(1):42-48. https://doi.org/10.1007/s11606016-3826-8

3. Axon RN, Turner M, Buckley R. An Update on Inpatient Hypertension Management. Curr Cardiol Rep. 2015;17(11):1-8. https://doi.org/10. 1007/s11886-015-0648y
4. Weiss A, Rudman Y, Beloosesky Y, Akirov A, Shochat T, Grossman A High blood pressure variability predicts 30-day mortality but not 1-year mortality in hospitalized elderly patients. Blood Press. 2017;26(5):259263. https://doi.org/10.1080/08037051.2017.1300859

Publisher's Note Springer Nature remains neutral with regard to jurisdictional claims in published maps and institutional affiliations. 